Journal of

Epidemiology and Community Health, 1979, 33, 74-77

\title{
The sex differential in ischaemic heart disease: trends by social class 1931 to 1971
}

\author{
MABEL L. HALLIDAY AND TERENCE W. ANDERSON \\ From the Department of Preventive Medicine and Biostatistics, University of Toronto
}

SUMMARY The comparison of trends in ischaemic heart disease (IHD) mortality in different social classes is confounded by historical changes in diagnostic techniques and statistical classification, and possibly by different standards of diagnostic accuracy in the different social classes. These problems can be circumvented by taking advantage of the fact that in middle age (45 to 64) the IHD death rate is much higher in men than in women. This large sex differential is not present in any of the other causes of death with which IHD might easily be confused and it is therefore relatively unaffected by diagnostic errors and variation in classification. The changes that have occurred in the sex differential in Social Classes I and V in England and Wales between 1931 and 1971 confirm anecdotal clinical reports that the male vulnerability to IHD appeared first in Social Class I (professional). By 1971 Social Class V (unskilled) had caught up, and the men in these two social classes now experience an almost identical excess in cardiovascular death rate compared with their wives.

It has been suggested that much of our modern burden of ischaemic heart disease (IHD) is the result of modern technology and affluence that have led inter alia to the almost complete disappearance of physically strenuous occupations and to an over-rich diet.

If this were true, it might reasonably be assumed that IHD would have been a problem first for the traditionally affluent and non-manual groups in society-doctors, lawyers, business executives, etc. - and only in more recent years for the traditionally non-affluent unskilled manual workers who have lost the protective effect of a strenuous life and a poor diet.

There is some anecdotal support for this belief, since Osler (1910) and others commented in the early years of this century that 'severe angina', the equivalent in modern terms to myocardial infarction and sudden death, was almost entirely restricted to professional and business men. However, it is very difficult to confirm these observations through study of mortality statistics or other quantitative data because of the great changes in diagnostic accuracy and fashion of the last few decades, and the different standards of medical care that were, and to some extent possibly still are, available to persons ot different socioeconomic status.

Fortunately many of these methodological problems can be circumvented by making use of the characteristic sex differential of IHD (Anderson, $1973 \mathrm{a} ; 1973 \mathrm{~b} ; 1978)$ and this technique is here applied to the data contained in the decennial supplements on occupational mortality for England and Wales between 1931 and 1971 (Registrar General, $1938 ; 1958 ; 1971 ; 1978$ ).

At first we intended to compare specific occupations such as physicians, clergymen, coal miners, etc., but not all of the decennial supplements gave sufficiently detailed mortality figures, particularly for the wives of men in those occupations. This analysis is therefore based on a comparison of death rates in Social Class I (professional) and Social Class V (unskilled). Rates in Social Classes II, III, and IV were largely intermediate to those in I and V and have been omitted for the sake of simplicity. The age group 45-64 has been used throughout in order to avoid the uncertainties of occupational classification in persons over 65 , and because of the small number of deaths under the age of 45 .

\section{Materials and methods}

The social class classification of England and Wales has undergone a number of modifications over the years, but these changes have mainly affected the three intermediate social classes. The definitions of Social Classes $\mathrm{I}$ and $\mathrm{V}$ have remained relatively stable. (Leete and Fox, 1977). Furthermore, changes in social class classification tend to affect men and their wives equally, so that any errors should have only a small effect on the difference between the rates in the two sexes. Social Class I consists of 
professional people such as physicians, lawyers, clergymen, bank managers, professional engineers, and so on, while Social Class V covers unskilled occupations such as dock, building, farm, and general labourers, and railway porters.

Between 1931 and 1971 the number of men aged 45 to 64 in Social Class I rose from 130000 to 235000 , or from $3 \cdot 2 \%$ to $4 \cdot 1 \%$ of the total for all five social classes. In the same period, Social Class V decreased in size from 696000 to 464000 , or from $17 \cdot 1 \%$ to $8 \cdot 1 \%$ of the total. There were similar changes in the number of married women in the two social classes.

Death rates for the age group 45 to 64 were calculated from death and population data for the age groups 45-54 and 55-64, taken from the decennial supplements (Registrar General, 1938; $1958 ; 1971 ; 1978)$ and standardised to the distribution of males aged 45 to 64 in the total population of England and Wales at the 1961 census (proportions approximately 0.55 and 0.45 ).

Because of the war, no data are available for the year 1941. In the 1951 supplement, no figures were provided for 'total circulation', and in the Table the figures for 1951 in the category 'other circulation' have therefore been taken as equal to those in 1961 .

The following terms were embraced by the diagnostic categories listed in the Table. The corresponding ICD numbers are shown for 1931; 1951 and 1961 (same: in italics); and 1971.

Acute ischaemic heart disease: including angina pectoris, coronary thrombosis, myocardial infarction, arteriosclerotic heart disease $(94: 420: 410,411,413)$.
Chronic ischaemic heart disease: including myocardial degeneration, fatty heart, and (1971) any case of ischaemic heart disease lasting more than eight weeks (93: 422 : 412).

Valvular heart disease: including rheumatic heart disease, other endocarditis (91, 92 : 410-416, 421 : 393-398).

Cerebrovascular disease: including stroke, apoplexy, cerebral haemorrhage and cerebral thrombosis $(82,97(1,2): 330-334$ : 430-438).

Nephritis: including Bright's disease and nephrosis (130-132: 590-594: 580-584).

\section{Results}

The Table shows that in 1931 the recorded death rate from angina pectoris and other IHD-specific terms was almost four times greater in men of Social Class I than in men of Social Class V-121 compared with 33 per $100000^{*}$. However, it is generally accepted that some deaths now certified as due to IHD would in 1931 have been ascribed to 'myocardial degeneration' and other similarly non-specific terms. These non-specific diagnoses may therefore be added to the IHD-specific terms in order to get a more reasonable estimate of total IHD mortality.

When this is done with the present data, the result is that men in Social Classes I and V appear to have approximately the same total IHD death rate in 1931-234 compared with 210.

*All rates quoted in this paper are annual rates per 100000 population.

Table Death rates per 100000 for men and married women aged 45 to 64 in Social Classes I and V, England and Wales 1931 to 1971

\begin{tabular}{|c|c|c|c|c|c|c|c|c|c|}
\hline & $\begin{array}{l}\text { Social } \\
\text { class }\end{array}$ & Men & $\begin{array}{l}1931 \text { Married } \\
\text { women }\end{array}$ & Men & $\begin{array}{l}1951 \\
\text { Married } \\
\text { women }\end{array}$ & Men & $\begin{array}{l}\text { Married } \\
\text { women } \\
\end{array}$ & Men & $\begin{array}{l}1971 \\
\text { Married } \\
\text { women } \\
\end{array}$ \\
\hline $\begin{array}{l}\text { Angina pectoris, acute IHD } \\
\text { Myocardial degeneration, } \\
\text { chronic IHD }\end{array}$ & $\begin{array}{l}\mathbf{I} \\
\mathbf{V} \\
\mathbf{I} \\
\mathbf{V}\end{array}$ & $\begin{array}{r}121 \\
33 \\
113 \\
177\end{array}$ & $\begin{array}{r}23 \\
13 \\
57 \\
140\end{array}$ & $\begin{array}{r}409 \\
239 \\
41 \\
79\end{array}$ & $\begin{array}{l}69 \\
70 \\
24 \\
45\end{array}$ & $\begin{array}{r}385 \\
422 \\
9 \\
27\end{array}$ & $\begin{array}{r}59 \\
122 \\
4 \\
15\end{array}$ & $\begin{array}{r}359 \\
420 \\
69 \\
94\end{array}$ & $\begin{array}{r}52 \\
116 \\
10 \\
33\end{array}$ \\
\hline ('Total IHD') & $\stackrel{\mathbf{I}}{\mathbf{V}}$ & $\begin{array}{l}234 \\
210\end{array}$ & $\begin{array}{r}80 \\
153\end{array}$ & $\begin{array}{l}450 \\
318 \\
\end{array}$ & $\begin{array}{r}93 \\
115 \\
\end{array}$ & $\begin{array}{l}394 \\
449 \\
\end{array}$ & $\begin{array}{r}63 \\
137 \\
\end{array}$ & $\begin{array}{l}428 \\
514 \\
\end{array}$ & $\begin{array}{r}62 \\
149\end{array}$ \\
\hline $\begin{array}{l}\text { Valvular heart disease } \\
\text { Cerebrovascular } \\
\text { Other diseases of circulation } \\
\text { Nephritis }\end{array}$ & $\begin{array}{l}I \\
\mathbf{V} \\
\mathbf{I} \\
\mathbf{V} \\
\mathbf{I} \\
\mathbf{V} \\
\mathbf{I} \\
\mathbf{V}\end{array}$ & $\begin{array}{r}82 \\
115 \\
126 \\
110 \\
24 \\
24 \\
90 \\
71\end{array}$ & $\begin{array}{r}60 \\
109 \\
81 \\
118 \\
11 \\
13 \\
43 \\
69\end{array}$ & $\begin{array}{r}30 \\
50 \\
145 \\
117 \\
64 \\
108 \\
24 \\
20\end{array}$ & $\begin{array}{r}32 \\
50 \\
113 \\
112 \\
26 \\
71 \\
11 \\
17\end{array}$ & $\begin{array}{r}23 \\
40 \\
94 \\
140 \\
64 \\
108 \\
8 \\
16\end{array}$ & $\begin{array}{r}20 \\
52 \\
56 \\
117 \\
26 \\
71 \\
5 \\
9\end{array}$ & $\begin{array}{r}16 \\
22 \\
76 \\
122 \\
62 \\
105 \\
6 \\
11\end{array}$ & $\begin{array}{r}13 \\
31 \\
53 \\
93 \\
20 \\
62 \\
3 \\
5\end{array}$ \\
\hline (Total cardiovascular-renal) & $\underset{\mathbf{V}}{\mathbf{I}}$ & $\begin{array}{l}556 \\
530\end{array}$ & $\begin{array}{l}275 \\
462\end{array}$ & $\begin{array}{l}713 \\
613\end{array}$ & $\begin{array}{l}275 \\
365\end{array}$ & $\begin{array}{l}583 \\
753\end{array}$ & $\begin{array}{l}170 \\
386\end{array}$ & $\begin{array}{l}588 \\
774\end{array}$ & $\begin{array}{l}151 \\
340\end{array}$ \\
\hline All other causes & I & $\begin{array}{r}980 \\
1316\end{array}$ & $\begin{array}{l}678 \\
564\end{array}$ & $\begin{array}{r}744 \\
1093\end{array}$ & $\begin{array}{l}507 \\
477\end{array}$ & $\begin{array}{r}459 \\
1157\end{array}$ & $\begin{array}{l}330 \\
519 \\
\end{array}$ & $\begin{array}{l}433 \\
978\end{array}$ & $\begin{array}{l}379 \\
510\end{array}$ \\
\hline ALL CAUSES & $\underset{\mathbf{V}}{\mathbf{V}}$ & $\begin{array}{l}1536 \\
1846\end{array}$ & $\begin{array}{r}953 \\
1282\end{array}$ & $\begin{array}{l}1457 \\
1706\end{array}$ & $\begin{array}{l}782 \\
842\end{array}$ & $\begin{array}{l}1042 \\
1910\end{array}$ & $\begin{array}{l}500 \\
905\end{array}$ & $\begin{array}{l}1021 \\
1752\end{array}$ & $\begin{array}{l}530 \\
850\end{array}$ \\
\hline
\end{tabular}


Between 1931 and 1951, the total IHD rates increased in the men of both these social classes, especially in men of Social Class $\mathrm{I}$, in whom the rate increased from 318 to 450 . By 1961 Social Class I had dropped back to 394, while Social Class V had increased to 449, but by 1971 both rates had increased again, class $I$ to 428 , and class $V$ to 514 , or both approximately double what they were in 1931 . (By 1961 the non-specific rates had become very small. Their increase in 1971 was due to the addition of 'chronic IHD'-defined as any episode lasting more than eight weeks).

In married women in 1931 the death rate from angina, etc. was higher in Social Class I (23) than in Social Class V (13). The addition of the nonspecific IHD terms reversed this order so that class $\mathrm{V}$ women appeared to have almost double the rate of class I women (153 to 81). By contrast with the increase seen in the male rates, between 1931 and 1971 the total IHD rates in wives either stayed the same or went down, with Social Class V staying approximately the same (153 to 149$)$, and Social Class I dropping from 80 to 62 .

It is difficult to assess the validity of these apparent changes in IHD mortality, either in men or in women. In 1931 the frequency of ischaemic heart disease may well have been underestimated, especially in Social Class V, but by including 'catch-all' terms such as myocardial degeneration we may over-compensate and end up with falsely high figures. That this may indeed have occurred with the 1931 figures is suggested by the subsequent fall in 'total IHD' rate in females of Social Class I, since it is unlikely that this group would have experienced a true decline in IHD mortality at the same time as male rates were increasing. A more likely explanation is that the 1931 'total IHD' figure was too high.

Diagnostic techniques had improved a great deal by 1971 and certified causes of death should therefore have been more reliable, but 'coronary thrombosis' may have replaced 'myocardial degeneration' as an acceptable 'catch-all' term in deaths of uncertain aetiology. Once again, therefore, it is possible that our estimates of total IHD mortality are exaggerated, particularly in Social Class V, in which a precise determination of cause of death (either pre or post mortem) is likely to occur less frequently than in Social Class I.

Here the characteristic sex differential of IHD can be used to good effect. We have previously shown that-whatever the underlying reasons-the type of illness recognised today as IHD is unique among the cardiovascular-renal diseases in showing a much higher incidence in males than in females (Anderson, $1973 a ; 1973 b)$. Furthermore, changes in diagnostic accuracy and statistical classification within each social class will tend to affect the sexes equally, so that both the ratio of the rates $(M / F)$ and the difference between the rates $(\mathbf{M}-\mathbf{F})$ are relatively unaffected even by large changes in these confounding variables (Anderson, 1978).

The male/female ratio for 'total IHD' has more than doubled in both social classes between 1931 and 1971, and the ratio in Social Class I has remained approximately twice as high as the ratio in Social Class V (Fig. 1). For the broader classification of

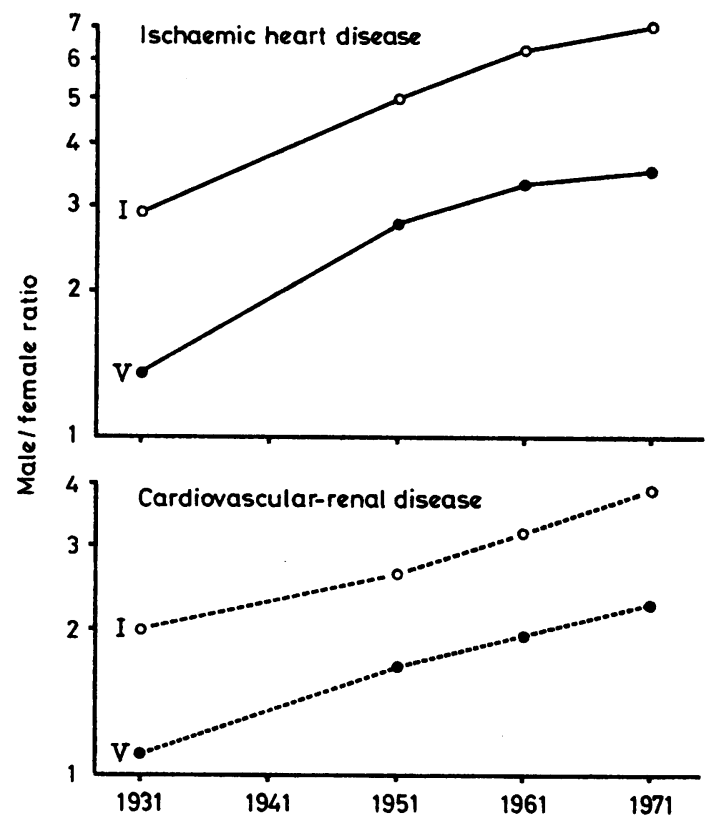

Fig. 1 Ratio of male to female death rate in Social Classes I and V for 'total IHD' deaths (see Table) and for total cardiovascular-renal disease, England and Wales, ages 45 to 64.

A logarithmic (ratio) scale is used for the vertical axis.

cardiovascular-renal disease the same generalisations hold true, but all the sex ratios tend to be lower because of the dilution of the IHD deaths with nonIHD cases. This is a disadvantage of the sex ratio approach, for although it is obviously safer to use a very broad classification when comparing rates over a long period of time, this results in a loss of sensitivity.

This loss of sensitivity is largely avoided by working with the difference in the rates, or the 'male excess'. Here, the inclusion of non-IHD diagnoses has little or no diluting effect because the non-IHD rates are usually almost equal, and the difference between them close to zero. Using this approach it can be seen 
that in 1931 there was already a substantial male excess in Social Class I but hardly any in Social Class V (Fig. 2). By 1951 the male excess in Social

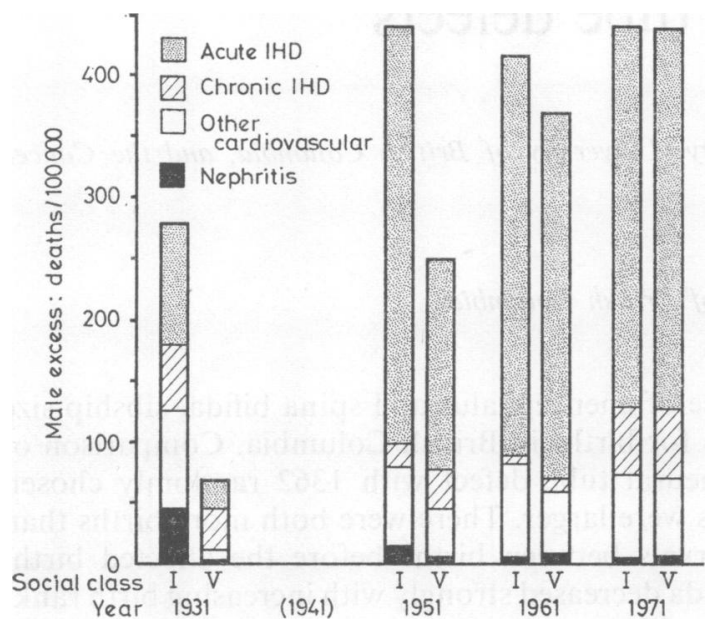

Fig. 2 Male excess (male death rate minus female death rate) in Social Classes $I$ and $V$ for total cardiovascular-renal disease, England and Wales, ages 45 to 64 .

An arithmetic scale is used for the vertical axis.

Class I had reached 438 and then changed little over the next 20 years, while in Social Class V the male excess rose steadily, and by 1971 equalled that of Social Class I.

It is interesting that almost half of the male excess in Social Class I in 1931 involved nephritis or 'other' cardiovascular disease. The latter may well have included terms that are virtually synonymous with IHD, such as generalised arteriosclerosis, but many of the nephritis deaths may have actually been misdiagnosed IHD, since a large male excess has never been characteristic of nephritis (Anderson, 1978).

\section{Discussion}

The social class difference seen in male excess in 1931 is consistent with anecdotal clinical reports that fatal IHD in men was initially more common in the well-to-do. It is, of course, theoretically possible that the subsequent changes in both male excess and sex ratio could have resulted from a decline in the corresponding female death rates, but this seems extremely unlikely in the present situation. Not only have women been exposed to much the same IHD risk factors as men (so that one would expect to see, if anything, a rise in their IHD mortality) but the sheer magnitude of the present IHD death rates makes it almost inconceivable that in earlier years a large proportion of these deaths could have been so grossly misdiagnosed as to be classified outside the broad cardiovascular-renal grouping.

These results are compatible with the belief that in the past a strenuous job and a poor diet afforded some protection against IHD to men of Social Class V. However, it should be borne in mind that these are not the only aspects of life style that have changed in the past four decades, and it is possible that a number of other factors such as the increased consumption of cigarettes and perhaps the general stress of modern life may have contributed to the increased vulnerability of males in Social Class V.

We thank Mrs. J. Cleathero for technical assistance. This work was supported by grant PR 484 from the Ontario Ministry of Health. The research was carried out in partial fulfilment of an MSc degree at the University of Toronto (M.L.H.).

Reprints from Dr. Mabel L. Halliday, Department of Preventive Medicine and Biostatistics, University of Toronto, Toronto, Canada M5S 1A8.

\section{References}

Anderson, T. W. (1973a). Mortality from ischemic heart disease: changes in middle-aged men since 1900. Journal of the American Medical Association, 224, 336-338.

Anderson, T. W. (1973b). The changing pattern of ischemic heart disease. Canadian Medical Association Journal, 108, 1500-1504.

Anderson, T. W. (1978). A new view of heart disease. New Scientist, 77, 374-376.

Leete, R., and Fox, J. (1977). Registrar General's social classes: origins and uses. Population Trends, 8, 4-7.

Osler, W. (1910). The Lumleian lectures on angina pectoris. Lancet, 1, 839-844.

Registrar General (1938). Decennial Supplement on Occupational Mortality in 1931. HMSO: London.

Registrar General (1958). Decennial Supplement on Occupational Mortality in 1951. HMSO: London.

Registrar General (1971). Decennial Supplement on Occupational Mortality in 1961. HMSO: London.

Registrar General (1978). Decennial Supplement on Occupational Mortality in 1970-72. HMSO: London. 